\title{
DISCUTINDO SOBRE O FRACASSO ESCOLAR NA PERSPECTIVA DE BERNARD CHARLOT: EM FOCO UMA ESCOLA PÚBLICA PAULISTA DE EDUCAÇÃO BÁSICA
}

DISCUSSING ON SCHOOL FAILURE IN VIEW OF BERNARD CHARLOT: IN FOCUS A PUBLIC SCHOOL OF BASIC EDUCATION PAULISTA

DISCUTEN EN FRACASO ESCOLAR EN VISTA DE BERNARD CHARLOT: FOCO EN LA UNA ESCUELA PÚBLICA DE EDUCACIÓN BÁSICA PAULISTA

\section{Renato Bellotti Senicato ${ }^{1}$ Cláudia Beatriz de Castro Nascimento Ometto ${ }^{2}$}

RESUMO: Este artigo é fruto de um projeto de pesquisa financiado pelo CNPq/CAPES com período de vigência 2013-2014, desenvolvido em uma escola que atende alunos do Ensino Fundamental II e Ensino Médio. O projeto tem como objetivo compreender aspectos relativos à formação de leitores e escritores na escola básica, uma vez que ele se preocupa com o ingresso de alunos ainda não alfabetizados no sexto ano. Como parte do projeto mais amplo, desenvolvemos um projeto de iniciação científica a fim de compreender como Bernard Charlot compreende a escola, lugar de formação de jovens, uma vez que para ele é na relação com o saber que os sujeitos participam de modos diferenciados do processo de reprodução social, significando sua experiência escolar e transformando a si próprio. Metodologicamente, as Aulas de Trabalho Pedagógico Coletivo com os professores e aulas que envolviam o trabalho com leitura e escrita foram gravadas durante o ano de 2013 para que pudessem ser analisadas. Tomamos também como material de análise as correspondências eletrônicas trocadas entre os professores e os pesquisadores, bem como os materiais postados em redes sociais das quais fazíamos parte. Neste texto, problematizaremos a sutil interface entre as avaliações de larga escala e a produção do fracasso escolar relacionando-a ao alarde midiático. Aponta-se a resistência dos educadores às atuais políticas de responsabilização em educação, as quais atravessam o trabalho pedagógico "amarrando" o currículo a certos conteúdos nem sempre significativos a determinadas comunidades escolares. Ressalta-se, nesse processo, a relevância do trabalho coletivo em detrimento às determinações oficiais prescritivas.

PALAVRAS-ChAVE: Fracasso escolar. Avaliação da educação básica. Profissionais da educação.

ABSTRACT: This article is the result of a research project funded by CNPq / CAPES period of 20132014, developed in a school serving students from elementary education II and high school. The project aims to understand aspects of the training of readers and writers in the elementary school, since it is concerned with the admission of students not literate in the sixth year. As part of the wider project developed a research project to understand how Bernard Charlot comprises a school, place of training of young people, since for him is in relation with the knowledge that subjects participating in different modes of the process social reproduction signifying their school experience and transforming

\footnotetext{
${ }^{1}$ Especializado em Tecnologias, Formação de Professores e Sociedade pela Universidade Federal de Itajubá; graduando em Licenciatura em Filosofia pela Universidade Metodista de Piracicaba; atuando na área da Filosofia da Educação é aluno pesquisador do grupo "Walter Benjamin, Filosofia, Educação" - PPGE/UNIMEP e bolsista de IC do PIBIC/CNPq. Piracicaba (SP). E-mail: renatobellottisenicatto@ gmail.com

${ }^{2}$ Doutora em Educação pela Universidade Estadual de Campinas; Professora do Programa de Pós Graduação em Educação da Universidade Metodista de Piracicaba atuando no núcleo de Práticas Educativas e Relações Sociais no Espaço Escolar e não Escolar. Piracicaba (SP). E-mail: cbometto@ yahoo.com.br
}

Submetido em: 08/07/2014 - Aceito em: 04/08/2014.

\begin{tabular}{|c|}
\hline ETD-Educ. $t$ \\
\hline
\end{tabular}


itself. Methodologically, the Lessons Collective Pedagogical Work with teachers and classes that involved working with reading and writing were audio recorded during the year 2013 so they could be analyzed. We also take as material for analysis electronic correspondence exchanged between teachers and researchers, as well as the materials posted on social networks of which we were part. In this paper, we question the subtle interface between assessments and large-scale production of school failure relating it to media fanfare. Points to resistance from educators to current accountability policies in education, which cross the pedagogical work "tying" the curriculum does not always mean a certain school communities to certain contents. It is noteworthy, in this process, the importance of collective work in lieu of the prescriptive official determinations.

KEYWORDS: School failure. Evaluation of basic education. Education professionals.

RESUMEN: Este artículo es el resultado de un proyecto de investigación financiado por el CNPq / CAPES (2013-2014), desarrollado en una escuela que atiende a los estudiantes desde la primaria y educación de escuela secundaria. El proyecto tiene como objetivo comprender los aspectos de la formación de lectores y escritores en la escuela primaria, ya que se refiere a la admisión de los estudiantes no alfabetizadas en el sexto año. Como parte del proyecto más amplio desarrollado un proyecto de investigación para entender cómo Bernard Charlot comprende a escuela, ya que para él es en relación con el conocimiento de que los sujetos que participan en los diferentes modos de proceso reproducción social que significa su experiencia escolar y transformándose. Metodológicamente, las Lecciones Colectivas de Trabajo Pedagógico con los profesores y las clases que participan el trabajo con la lectura y la escritura eran de audio grabado en el año 2013. También tomamos como material la correspondencia electrónica intercambiada entre los profesores e investigadores, así como los materiales publicados en las redes sociales. En este trabajo, nos cuestionamos la interfaz sutil entre las evaluaciones a gran escala y la producción de fracaso escolar en relación a fanfarria los medios de comunicación. Apunta a la resistencia de los educadores a las políticas de rendición de cuentas corrientes en la educación, que cruzan el trabajo pedagógico "empatando" el plan de estudios a determinados contenidos. Es de destacar, en este proceso, la importancia del trabajo colectivo en lugar de las determinaciones oficiales prescriptivos.

PALABRAS ClAVE: Fracaso escolar. Evaluación de la educación básica. Profesionales de la educación.

\section{INTRODUÇÃ̃o}

Este artigo é resultado da interlocução entre projetos de pesquisa, e concentra sua problematização em um projeto de iniciação científica, que tem como objetivo identificar nas obras de Bernard Charlot, como o autor compreende a escola, lugar de formação de jovens, uma vez que para ele é na relação com o saber que os sujeitos participam de modos diferenciados do processo de reprodução social, significando sua experiência escolar e transformando a si próprio, a fim de relacionar com a discussão dos processos de singularização e constituição dos sujeitos - construção de identidades, nas palavras do autor , sejam eles professores em processo de formação centrada na escola ou alunos de camadas populares em processos escolares de formação básica. 
O projeto de IC vincula-se a um projeto mais amplo financiado pelo CNPq/CAPES para o período de vigência 2013-2014. Em parceria colaborativa com a universidade - por solicitação da equipe escolar -, o projeto mais amplo está sendo desenvolvido em uma escola da rede pública estadual na cidade de Piracicaba, no estado de São Paulo, que atende alunos do Ensino Fundamental II e Ensino Médio. A escola atende 1003 alunos divididos em três períodos e conta com, aproximadamente, 40 professores. Segundo caracterização do projeto político-pedagógico da escola (2011), a unidade está inserida em uma comunidade bastante carente, e muitos moradores e pais de alunos não têm uma profissão definida, o que os obriga a trabalhar em vários serviços temporários e informais, sendo que parte das famílias é atendida pelos programas sociais do governo federal e do município.

Durante reuniões de planejamento, no início de 2012, ao observarem os resultados insatisfatórios da escola nas avaliações externas, especificamente no Sistema de Avaliação de Rendimento Escolar do Estado de São Paulo (Saresp), compilados no boletim da Unidade Escolar, gestores e professores assustaram-se com os resultados dos alunos na passagem do ano de 2011 para o ano de 2012. A equipe escolar, preocupada com os alarmantes dados apresentados nas reuniões de planejamento, realizou no início de 2012 um levantamento com os alunos ingressantes no sexto ano a fim de identificar as condições de entrada deles no Ensino Fundamental II, uma vez que ela não dispunha de boletim específico do Índice de Desenvolvimento da Educação do Estado de São Paulo (Idesp), visto que os alunos eram oriundos de três diferentes escolas municipais da região.

O fator relevante para o estabelecimento da parceria colaborativa diz respeito aos resultados insatisfatórios da escola nas avaliações externas, o que compromete os índices da unidade escolar no ranking do Índice de Desenvolvimento da Educação do Estado de São Paulo (Idesp). Dados retirados do boletim da escola, disponibilizados pelo Governo do Estado de São Paulo, apontam que do ano de 2011 para o ano de 2012 houve uma queda de $24,2 \%$ no componente de língua portuguesa pelos alunos do nono ano, enquanto a meta esperada era a do aumento de 6,66\% em relação ao ano de 2011. Os dados, ao final de 2011, permitiram constatar que $92,79 \%$ dos alunos chegaram ao nono ano com índices abaixo do nível adequado; apenas 7,21\% estariam no nível adequado e nenhum aluno apresentou nível avançado no que diz respeito à língua portuguesa. 
Essa constatação instigou a equipe escolar a conhecer melhor também seus alunos ingressantes, no entanto, como não contavam com um boletim específico do Idesp para consulta, visto que os alunos são oriundos de três escolas municipais da região, a equipe decidiu realizar o próprio levantamento, sem que tivessem, no entanto, uma metodologia bem definida. Nesse levantamento constatou-se, no início do ano de 2012, o ingresso de $17 \%$ de alunos que não estariam alfabetizados e de $36 \%$ que teriam sérios problemas no desenvolvimento das atividades de leitura e de escrita relacionados às práticas de letramento.

Dados disponibilizados aos pesquisadores pela equipe escolar corroboram as diversas pesquisas realizadas na busca da compreensão do fracasso escolar que aponta que "o mais preocupante é que [...] ainda observamos o baixo desempenho dos sistemas de ensino, caracterizado pelas baixas taxas de sucesso escolar, sobretudo nos primeiros anos de escolaridade", relata o Inep.

Metodologicamente, entendemos que analisar os discursos dos professores durante as Aulas de Trabalho Pedagógico Coletivo - ATPCs -, as práticas docentes e de letramento em sala de aula, bem como os processos de significação de alunos e professores, tendo em vista não somente as atividades desenvolvidas, mas as formas como alunos e professores se apropriam dos conhecimentos socialmente produzidos é um procedimento metodológico que articula ensino e pesquisa, não se divorciando do mundo real. Essa tese sustenta-se em Vigotski (1989, p. 102), uma vez que para o autor "toda pesquisa tem por objetivo explorar alguma esfera da realidade".

Dessa forma, salientamos que a metodologia na qual se embasa o desenvolvimento do projeto ancora-se na perspectiva vigotskiana e de seus interlocutores, tendo como plano de possibilidades de investigação e ação os discursos produzidos na emergência da escola, ou seja, o lócus onde as problemáticas enfrentadas e expostas, como nos chama atenção Vigotski, para que as questões devam ser enfrentadas onde são produzidas, ou seja, nas condições reais em que se constituem, explorando, dessa maneira, a condição concreta de produção dos problemas e de suas possíveis soluções.

Os encaminhamentos metodológicos da pesquisa utilizaram dados e variáveis quantitativas para sua implementação, que foram elaborados pela própria equipe escolar sem um rigor e clareza acerca dos métodos, e chamam a atenção dos pesquisadores para os problemas enfrentados pela equipe da escola. Uma vez implementada a pesquisa, a principal 
fonte de dados passa a ser de natureza discursiva, por meio do acolhimento e da problematização das falas que emergem do cotidiano da escola. Isso porque os enunciados produzidos na realidade escolar caracterizam as singularidades dos percursos enfrentados.

Os enunciados produzidos na realidade dos enfrentamentos da escola, que são acolhidos pela equipe de pesquisa, são analisados segundo princípios de análise enunciativa, proposta por Bakhtin, segundo os quais a análise verbal é tomada como unidade de análise e sentido pela interação verbal, que desvela a ligação entre elas, apresentando as condições concretas em que se realizam e são produzidas, caracterizando na linguagem a materialidade dos elementos constitutivos de determinada situação. Dessa maneira, o estudo realiza-se entre "as formas e os tipos de interação verbal em ligação com as condições concretas em que se realiza”. (BAKHTIN, 2002, p. 124).

Dessa forma, com relação ao método, é possível pontuar que a pesquisa caracteriza-se como de cunho qualitativo, descritivo e analítico. A escuta e o acolhimento das falas que emergem do cotidiano e realidade da escola colocam o pesquisador na posição daquele que ouve, aproximando-se dos fenômenos que lhes são apresentados, mas também descreve e teoriza, aproximando esses fenômenos do aprofundamento necessário para a interlocução entre teoria e prática. Esse movimento atento do pesquisador possibilita-nos pensar, com Charlot (2000, p. 15), que "o pesquisador deve, portanto, procurar voltar a uma certa ingenuidade pré-sociológica para proteger-se contra as evidências".

Nos limites deste texto, tratamos a temática do fracasso escolar abordando-o como objeto complexo, "sociomediático", tal como nos explicita Charlot (2000, p. 13) ao discuti-lo como objeto de pesquisa inencontrável, ou seja, constantemente trazido à tona nas diversas formas de divulgação com relação ao universo educacional - exemplo que se torna visível quando se pretende dialogar sobre a educação e $\operatorname{logo}$ as primeiras palavras dirigidas com relação à temática fazem alusão aos níveis insatisfatórios alcançados pelos alunos da escola básica brasileira nas avaliações de larga escala implementadas no Brasil. Nessa perspectiva a discussão sobre o "fracasso escolar" envolve um horizonte de análise que é demasiado amplo e não pode ser simplificado, categorizado ou matematizado de forma simples.

Pontuar que o horizonte de análise acerca do "fracasso escolar" é amplo, portanto, não simplificável, passível de ser categorizado ou matimatizado, é pontuar a densa responsabilidade acerca da realização de estudos sobre seus objetos, que são reais, 
polissêmicos e embíguos. O "fracasso escolar", na qualidade de objeto que se constitui na ausência do rigor analítico em que se deve colocar o pesquisador, ilustrado pelo autor como posição de "ingenuidade pré-sociológica", assume a roupagem de um objeto discursivo atrativo com finalidade ideológica. Disso incorre o fato de que não pode ser simplificado ou reduzido, posto que sempre demandará profunda e densa análise concentrada na materialidade e na concretude dos símbolos em que as relações são caracterizadas, ou seja, a realidade e as experiências enfrentadas pelos alunos, pois "tais objetos remetem sempre a práticas ou situações e supostamente explicam o 'vivido' e a 'experiência”". (CHARLOT, 2000, p. 13).

\section{O “FRACASSO ESCOLAR" COMO OBJETO COMPLEXO E "SOCIOMEDIÁTICO"}

Iniciamos nossa discussão tomando para além dos enunciados dos professores em reuniões de ATPCs, duas postagens no Facebook - um diálogo aberto entre a diretora da escola e o ex-coordenador do Ensino Médio - a respeito do trabalho desenvolvido durante o ano de 2013 e dos resultados alcançados nas avaliações externas. Também de forma sociomediática, suas réplicas são enunciados expressivos de educadores da escola básica acerca das avaliações de larga escala às quais estão submetidos, o que nos reafirma a importância da discussão entre esse tipo de avaliação e sua forma de divulgação na interface com a produção do fracasso escolar, seja de alunos ou professores. Destacamos que todos os nomes dos sujeitos são fictícios para resguardar a identidade dos participantes da pesquisa.

Vejamos o diálogo.

"Renata (diretora): Prezados professores e funcionários da escola estadual professor [nome da escola]. Neste fim de semana vi o resultado do Idesp 2013, fiquei um tanto decepcionada com a meta atingida, que foi de $71 \%$ no ensino fundamental e $0 \%$ no ensino médio. Eu acompanhei o trabalho árduo de muitos de vocês, a seriedade, o comprometimento, o envolvimento com o processo ensino aprendizagem dos alunos. Refleti sobre todas as ações da nossa escola, as avaliações, projetos, as ATPC, as potencialidades, as fragilidades da escola. É evidente que teremos que arregaçar as mangas, descobrir onde estamos falhando e avançar neste processo. De que maneira? Vamos mais uma vez descobrir juntos! Eu não aceito esse resultado e tenho certeza que muitos de vocês que trabalham dignamente nesta escola, também não. A forma de o governo avaliar as escolas públicas é assim! Então, temos que encará-la de frente e com competência. Muito obrigado. (Postado no facebook em 28/03/2014).

Caio (ex-coordenador): Olá pessoal. Concordo com tudo isto que a Renata disse. E digo mais: a política de bonificação do Estado nunca será justa. O Estado só está preocupado com que os alunos saibam tudo sobre um currículo baseado no mínimo do mínimo e que diga-se de passagem, não é atualizado desde sua implantação (mudança de exercícios ou inversão de textos não são mudanças). Todos nós sabemos que o currículo não é só um pedaço de papel, a maioria de nós que tivemos formação em educação sabemos que existem outros currículos e valores que nos formam. Valores como solidariedade, amizade, respeito as diferenças, tolerância e formação para o mundo, sempre 
foram premissas desta escola, porém, infelizmente isto não cai nas provas do Saresp, e todo ano parece-me que somos jogados no fundo do poço por não termos feito nossa parte. Mas será que não fizemos? Todos vocês já viram quantos cidadãos nós formamos (basta encontrar com alguns ex-alunos fora da escola), é nítida a diferença que nós fizemos em suas vidas. O dia que isto será reconhecido está longe de vir, pois esbarramos na burocracia que permeia nosso país e dos pseudoeducadores que formulam estas leis. A meu ver falta ainda no [nome da escola] colocarmos na cabeça de nossos alunos que o papel dele como educando é o de aprender o currículo e ser capaz de ir bem em uma avaliação externa, e que nossos professores tem que se preocupar e muito com os conteúdos que não estão sendo assimilados, buscando as causas e promovendo alternativas para que a aprendizagem aconteça. Mas não podemos nunca nos esquecer do lado humano de nossa escola, na convivência que faz todos ter saudades desta escola (inclusive eu), e de que nossos professores estão caminhando para um autoconhecimento que já deu ótimos frutos para todos (não necessariamente em dinheiro). Estou em uma escola que realmente irá alcançar os resultados esperados, mas isso me trará uma satisfação meramente parcial, pois minha autonomia será reduzida a fórmula: você ensina e entrega a documentação exigida, os seus superiores ficam felizes com a documentação e seu aluno tira uma nota boa na avaliação externa. Será que as escolas serão reduzidas a isto? Estou em momentos profundos de meditação sobre tudo e sobre todos, e por isso me estendi tanto. (Resposta do coordenador do ensino médio em 2013 à postagem da diretora, em 29/03/2014)"”

Entendemos que a educação, para além das prescrições oficiais, como nos alertou o ex-coordenador, corresponde ao espaço de tempo que dura do nascimento ao fim da vida dos indivíduos. Compreendemos por processos educacionais todos os instantes em que o ser humano está em relação com o mundo. É nessa relação que o sujeito se apropria de, e modifica elementos simbólicos para interpretar e organizar sua singularidade e o mundo segundo o movimento de suas afecções.

Ao mencionar "valores como solidariedade, amizade, respeito às diferenças, tolerância e formação para o mundo", a fala do ex-coordenador instaura no plano de imanência das relações escolares à potência valorativa imprescindível para a formação específica e humana, ou seja, não é só de conteúdos validados formalmente que a escola e seus atores se ocupam, mas, na qualidade de ambiente pulverizado e transpassado por símbolos enfrentados cotidianamente, carrega a potência de inscrever a educação como um valor. Dessa forma, "partindo do pressuposto de que a educação é um princípio, deparamonos com a inscrição da educação enquanto valor, sobretudo humano, no que tange que dela decorre a sustentação e a transmissão da própria comunidade humana, a cultura". (MARIGUELA; SENICATO, 2013, p. 129).

Dessa premissa advém a compreensão de sujeito que é ao mesmo tempo singular e social. Um sujeito que pertence a um grupo social, ocupando uma posição social, e ao longo da vida "produz sentidos e significados sobre si e o mundo, construindo sua singularidade. Portanto, na concepção de sujeito expressa por Charlot, não se fala de 'aspectos' sociais e individuais do sujeito - ele é sempre simultaneamente social e singular". (TRÓPIA; 
CALDEIRA, 2011, p. 372). Dessa forma, se escola é o ambiente em que se concentra essa multiplicidade, a educação "não é uma propriedade individual, mas pertence, por essência à comunidade". (JAEGER, 2011, p. 4).

Segundo essa concepção, a individuação, a construção de si, nas palavras de Charlot (2005) vai se configurando nas transformações do plano entre pessoas, socialmente (intersubjetivo) em um plano individual (intrasubjetivo), em condições concretas de produção. Essa constatação nos aproxima novamente dos estudos do autor ao ressaltar que é na relação com o outro e com o saber que nos singularizamos pelas atividades que realizamos.

Nesse sentido, os saberes que formam o conhecimento em sua esfera ampla, e o conhecimento de si mesmo como pessoa, nascem e se desenvolvem nas relações sociais, sendo, portanto, de natureza intersubjetiva. As relações dos sujeitos com os instrumentos e signos são sempre mediadas pelo outro, pelas práticas culturais e pela linguagem. Assim, assume-se o pressuposto de que os processos psicológicos emergem e consolidam-se relacionados aos modos de vida dos sujeitos em interação.

Mesmo compreendendo o processo educacional como amplo e aberto, recai sobre a escola o estatuto mantenedor do funcionamento da lógica de ensino e de aprendizagem segundo os conteúdos escolhidos e pontuados como necessários para o desenvolvimento da sociedade -mesmo que não nos indaguemos sobre qual sociedade é essa que se forma e a que interesses ideológicos atendem.

As falas da diretora e do ex-coordenador imprimem significados interessantes em nosso diálogo, pois aludem ao currículo, mas também referenciam a questão da criação de valores humanos no espaço da escola. Ao ressaltar, na primeira fala, que os índices de desempenho aferidos na última avaliação são insatisfatórios, há transposição da sensação da insatisfação gerada pelo baixo rendimento, enquanto a segunda fala ressalta que, mesmo assim, a escola privilegia e tem conseguido despertar valores. Essa constatação permite-nos inferir que a promoção de valores humanos, a qual o ex-coordenador lamenta porque "isto infelizmente não cai nas provas do Saresp", está dissociada dos objetivos específicos da escola com relação ao que prega seu currículo. Dessa forma, é necessário cuidado ao explorar o horizonte de elementos em torno da questão do "fracasso escolar", posto que encarado como fator "sociomediático", concentra densidade de cunho ideológico. Faz-se necessário, 
portanto, concentrar os diálogos em torno do aluno e seus enfrentamentos cotidianos com relação ao papel da escola, que aparentemente encontra-se em tensão.

O educador Bernard Charlot (2000), na obra Da relação com o saber: elementos para uma teoria, pontua o que se foi construindo, ideologicamente, como o conceito de "fracasso escolar". Ao evidenciar que o "fracasso escolar" é "um objeto de pesquisa inencontrável”, Charlot nos aproxima da discussão acerca de um objeto de pesquisa de cunho "sociomediático" por considerar que a frequente e exaustiva alusão aos níveis insatisfatórios alcançados pelos alunos simplificam as análises à medida que também reduzem a ampla gama de aspectos que deveriam acompanhar as discussões, simplificando os elementos que compõem o universo educacional.

Há um atravessamento nas práticas pedagógicas, no entrecruzamento das prescrições - das leis, dos conteúdos escolares definidos, dos modos de conduzir a prática pedagógica, das avaliações externas que lhes são determinadas (e de seus resultados) etc. - e das singularidades das práticas. Essas prescrições, ainda que tomadas com desconfiança por muitos, vão se naturalizando a favor da manutenção da ordem social vigente e, pelo poder da violência simbólica, já nos apontado pela Teoria da Reprodução de Bourdieu e Passeron (1975), impõem às classes dominadas a cultura e a linguagem das classes dominantes.

No ambiente escolar, há previsão de apropriação de determinados conhecimentos, bem como do desenvolvimento de habilidades e competências indispensáveis ao bom funcionamento e desenvolvimento da lógica social. Essa afirmação ilustra a base das tensões em que se projetam as relações entre os indivíduos, a sociedade e a escola e que, portanto, é pontual na análise que Charlot estabelece a respeito da pluralidade do objeto "fracasso escolar" e da teoria "da relação com o saber". Sobre essa afirmação reside a crítica às teorias da reprodução e as sociologias da diferença, pois "pouco a pouco, impôs-se a ideia de que estudar o fracasso escolar é analisar diferenças de sucesso ligadas a diferenças sociais. Aí está uma via de pesquisa muito interessante, mas que não explica a totalidade dos fenômenos evocados pela expressão 'fracasso escolar'”. (CHARLOT, 2000, p. 87).

A totalidade da vida é constituída por diversas facetas que, em análise das proposições teóricas de Charlot, podem ser divididas em três categorias, quais sejam: a epistemológica, a social e a subjetiva. Daí advém a proposição de que a teoria da relação com o saber deve ser baseada em uma sociologia do sujeito como... 
um ser humano, aberto a um mundo que não se reduz ao aqui e agora, portador de desejos movido por esses desejos, em relação com outros seres humanos, eles também sujeitos; [...] um ser social, que nasce e cresce em uma família (ou em um substituto da família), que ocupa uma posição em um espaço social, que está inscrito em relações sociais); [...] um ser singular, exemplar único da espécie humana, que tem uma história, interpreta o mundo, dá um sentido a esse mundo, à posição que ocupa nele, às suas relações com os outros, à sua própria história, à sua singularidade. (CHARLOT, 2000, p. 33).

As três categorias emolduram a realidade dos indivíduos e constituem os sujeitos como seres que integram um mundo e se relacionam com ele e com suas verdades estabelecidas, que estão em constante interlocução com o tempo, o espaço e os outros sujeitos, alterando, dessa forma, os símbolos que permeiam sua existência e, ressignificandoos, posto que possuem anseios e desejos íntimos que marcam o traço singular de cada indivíduo. Uma sociologia que prevê as relações com o saber e pretende promover a teoria da relação com o saber deve contemplar e considerar esses traços constitutivos dos sujeitos na pessoa dos alunos no interior da escola; mas "a escola converte a cultura e a linguagem dos grupos dominantes em saber escolar legítimo e impõe esse saber aos grupos dominados. Reforça-se assim, a dominação que determinados grupos exercem sobre outros, e perpetua-se a marginalização". (SOARES, 2002, p. 54).

Os bens simbólicos da classe dominante são legitimados na e pela escola. Ao contrário, há depreciação da cultura dos grupos dominados. Os alunos das classes populares não possuem o que Soares (2002, p. 61) denomina de "capital linguístico escolarmente rentável". Para a autora, a posse desse capital linguístico escolarmente rentável possibilita o sucesso na escola tal como a encontramos: no atravessamento entre as prescrições de uma classe dominante e das singularidades das práticas vividas nas escolas de bairros populares periféricos.

Nessa perspectiva, o fracasso se produz porque se espera que os sujeitos tenham aquilo que é valorizado pela escola e que pode não ser valorizado pelo aluno. Encontramos então a noção de "fracasso escolar", problematizada por Charlot, quando pontua que:

[...] esse não passa de um nome genérico, um modo cômodo para designar um conjunto de fenômenos que têm, ao que parece, algum parentesco. [...] afirmar que o "fracasso escolar" não existe, é recusar esse modo de pensar sob o qual insinuamse as ideias de doença, tara congênita, contágio, evento fatal. [...] o "fracasso escolar" não é um monstro escondido no fundo das escolas e que se joga sobre as crianças mais frágeis, um monstro que a pesquisa deveria desemboscar, domesticar, 
abater. O "fracasso escolar" não existe; o que existe são alunos fracassados, situações de fracasso, histórias escolares que terminam mal. (CHARLOT, 2000, p.16).

Essa concepção de "fracasso escolar" remete a um indicador de ausência, daquilo que falta, o que pode ser exemplificado nas palavras do autor por "uma recusa, uma transgressão - ausência de resultados, de saberes, de competências, recusa de estudar, transgressão das regras..." (CHARLOT, p.17).

Nessa direção, Soares (2002) aponta que uma primeira explicação elaborada na tentativa de justificar o fracasso escolar foi a "Ideologia do Dom". Tal teoria enfocava que as causas do sucesso ou do fracasso escolar deveriam ser buscadas nas aptidões, na inteligência e nos talentos dos indivíduos. Assim seria garantida a oportunidade de acesso à escola, mas sua concretização dependia das diferenças de aptidão existentes entre os indivíduos. Perspectiva essa que justifica a culpabilização da figura do aluno e a isenção do papel social da escola na medida em que, impondo regras, quando transgredidas, não se consegue lidar com a diferença sem o argumento patológico, portanto, é excluída dessa relação a esfera da subjetividade.

Charlot retoma o pensamento sociológico, pontuando que há duas maneiras indiretas para pensar o que não é, já que "a noção de fracasso escolar remete para fenômenos designados por uma ausência, uma recusa, uma transgressão - ausência de resultados, de saberes, de competência, recusa de estudar, transgressão de regras”. (CHARLOT, 2000. p. 17).

Na primeira dessas “duas maneiras de 'traduzir' o fracasso escolar para pensá-lo”, há referência à questão da ausência, pensa-se determinada condição com relação ao seu oposto, ou seja, aquilo que ela realmente não reflete, "isto é, pensar o não-ser em referência ao que, precisamente, ele não é. O fracasso escolar é uma diferença: entre alunos, entre currículos, entre estabelecimentos”. (CHARLOT, 2000, p. 17). Ora, pensar a diferença fora da relação é, determinar padrões considerados normais e aceitáveis e, quando algo a eles não responde, estabelecer, por meio do estigma, a noção de fracasso escolar pautada na diferença como uma posição, pois, "tais posições só fazem sentido como posições diferentes de outras posições". (CHARLOT, p. 17). 
Em comparação, a diferença passa de uma variável e se estabelece como uma condição já dada, pois, determinado aluno, por exemplo, não se enquadra em uma situação para a qual seus comportamentos são, na totalidade, já esperados. Isso permite-nos inferir a crítica de Charlot à sociologia da diferença quando pontua que essa "analisou o fracasso escolar [...] como diferença de posições entre alunos: o aluno em situação de fracasso ocupa no espaço escolar uma posição diferente da do aluno em situação de êxito [...]". (CHARLOT, 2000, p. 17). Dizer que o aluno fracassado não se enquadra em determinada situação para a qual seu comportamento é previamente esperado, significa analisá-lo com relação ao que é determinado como normal e aceitável; ou seja, "as posições respectivas, e não essas posições em si, é que permitem falar do fracasso escolar: que um jovem esteja no terceiro ano colegial [...] aos 17 anos só tem sentido quando se sabe que a maioria dos alunos entram no terceiro ano aos 14 ou 15 anos [...]”. (CHARLOT, 2000, p. 17).

Com relação à ausência, como apontado por Charlot, sobre a deficiência sociocultural, Soares (2002) ajuda-nos a compreender que outras explicações foram elaboradas no sentido de justificar a não aprendizagem dos alunos na escola pela posição que o indivíduo possui na hierarquia social. Nessa forma de explicação, alunos provenientes de classes social e economicamente desfavorecidas não aprendem os saberes ensinados pela escola porque encontram-se em defasagem cultural posto que vivem em grupos sociais nos quais lhes faltam cultura (CRISTOFOLETI; MARTANI; OMETTO, 2013).

Parece-nos que o evento sociomediático amplia a visibilidade ao não enquadramento de alguns alunos às situações esperadas pelas avaliações externas, possibilitando que recaia sobre o aluno o estigma, o rótulo da condição social e sua deficiência sociocultural. (CHARLOT, 2000, p. 17). O alarde dos resultados avança na direção de um aluno estigmatizado pela condição. Ao não responder de maneira satisfatória ao que dele é esperado, a estigmatização se dá por meio de pontuar sua origem, justificando como a causa do fracasso escolar, suas deficiências socioculturais.

$\mathrm{Na}$ segunda maneira indireta “de 'traduzir' o fracasso escolar”, o que norteia é a noção de experiência, ou seja, aquilo que o aluno enfrenta nas relações estabelecidas no ambiente escolar que referenda "as situações nas quais os alunos se encontram em um momento de sua história escolar, as atividades e condutas desses alunos, seus discursos". (CHARLOT, p. 17). Nessa esfera, o "fracasso escolar" é estudado de dentro, pois elaborar 
uma análise do aluno fracassado também é evidenciar as noções de diferença e de falta, uma vez que as dificuldades estão postas.

Ocorre que, a priori, a expressão "fracasso escolar" tem sido e pode ser utilizada para denominar várias coisas - do fracasso do aluno ao do professor e da escola pública -, pois abarca uma realidade social, que é portanto ampla, múltipla. Aí consiste a conceituação dessa expressão como objeto "sociomediático". Charlot nos diz que:

\begin{abstract}
A expressão "fracasso escolar" é uma certa maneira de verbalizar a experiência, a vivência e a prática; e, por essa razão, uma certa maneira de recortar, interpretar e categorizar o mundo social. Quanto mais ampla a categoria assim construída, mais polissêmica e ambígua ela é. Dessa maneira, a noção de fracasso escolar é utilizada para exprimir tanto a reprovação em uma determinada série quanto a não-aquisição de certos conhecimentos ou competências; refere-se, tanto aos alunos da primeira série do primeiro grau que não aprendem a ler em um ano, como aos que fracassam no "bacharelado", ou até no primeiro ciclo superior; ela se tornou, mesmo, tão extensa, que uma espécie de pensamento automático tende hoje a associá-la à imigração, aos desemprego, à violência, à periferia. (CHARLOT, 2000, p.14).
\end{abstract}

A noção de "fracasso escolar" vai apresentando certa densidade ideológica, pois acaba por condensar várias temáticas sociais importantes na esfera de uma única terminologia, ou seja, a ideia que se forma a partir disso torna-se objeto de discurso, "conjurando poderes". (FOUCAULT, 2008, p. 8-9). Dada a multiplicidade que envolve a análise da noção de "fracasso escolar", o uso desse tipo de discurso pode ser alterado e dirigido para qualquer esfera que o componha.

Novamente encontramos a simplificação dos elementos veiculados pela mídia recaindo sobre o professor e não mais sobre os alunos ao alardear a má-formação dos professores e a pobreza da qualidade das relações que são possibilitadas aos alunos - na escola, pela incompetência do professor. Segundo Charlot, são as insistentes tentativas em matematizar e quantificar os elementos que compõem o universo educacional, que é humano, que provocam o reforço da noção de fracasso. Charlot evidencia essas proposições quando pontua que:

Todas as noções que encobrem, pois, práticas e experiências muito diversas e se beneficiam ao mesmo tempo de uma espécie de evidência encontram-se na encruzilhada de múltiplas relações sociais. Enquanto "noções-encruzilhadas", exercem um papel "atrativo". Enquanto inscritas em relações sociais de natureza diversa, prestam-se muito bem para um uso ideológico: o debate sobre o fracasso escolar enquanto desigualdade social pode ser desviado para a questão da ineficácia pedagógica dos docentes... e vice-versa. (CHARLOT, 2000, p.14). 
Em um contexto que compreende um campo de imanência que vai do âmago da esfera subjetiva ao pontual da objetividade política, quando a educação não atinge seus objetivos, traçamos um quadro que hoje se denomina "fracasso escolar". O que fica evidente nas palavras preliminares de Bernard Charlot quanto à questão do "fracasso escolar" é a sua densa complexidade, pois essa noção traz em seu bojo a influência de pontuais esferas de organização da vida cultural e social. A atenção na análise desses objetos deve ser ampla, aprofundada e, como indica Charlot, um pouco ingênua, para que o pesquisador fuja de evidências muito latentes, fugindo daquilo que a moda mediática convencionou estipular como real e aceitável. (CHARLOT, 2000, p. 15). O educador francês aponta-nos a necessidade de um olhar mais "limpo", uma análise que ouça todos aqueles que estão envolvidos nos processos educacionais estudados, algo que ocorre por meio da descrição e da escuta e, depois vai a formulação do conceito e da teoria. (CHARLOT, p. 15-16).

\section{CONSIDERAÇõES FINAIS}

Segundo Charlot, é verdade que todos os fenômenos abarcados na realidade interpretativa da relação de fracasso são reais, existem, mas é necessário pontuar que, nenhum desses objetos é analisável redutivamente como sendo determinante do "fracasso escolar". (2000, p. 16). Parece-nos claro que, reduzir todos esses elementos em um único objeto como a síntese de todo problema, acaba culminando na pontuação de ser esse objeto a figura do aluno. Tem se tornado comum, ao ouvirmos falar sobre o fracasso escolar, que a figura do aluno seja trazida para o centro da discussão e que, boa parte dos argumentos que carregam a negatividade de determinado objeto acabem por culpabilizá-lo. A discursividade "enfatiza a crise de ineficácia do sistema educacional brasileiro, no bojo da qual está o desempenho das escolas e dos professores, de um lado, como fator de resultados insatisfatórios de aprendizagem dos alunos tais como os aferidos pelo Saeb". (COELHO, 2008, p. 231).

Extraídas dos diálogos no grupo em que ocorre a pesquisa (projeto submetido ao Comitê de Ética em Pesquisa - CEP - da Unimep, aprovado em 26/02/3013, consta sob o número de protocolo 01/13), surgem as provocantes falas dos professores:

Elen (Matemática): Às vezes você, como professor, tenta de várias formas fazer com que aquela criança ou aquele adolescente faça alguma coisa, e eles não fazem. [...] eles não tem interesse em fazer. Mas o sistema impõe. Ele impõe! Você precisa 
fazer isso, precisa fazer aquilo. Precisamos ensinar o conteúdo tradicional, pois é o que cai nos exames, no vestibular.

Fabíola (Português): [...] nesse final de semestre tudo se volta para o SARESP!

Paula (Matemática): Porque você precisa colocar o conceito no papel, você precisa apresentar números... Essa é a verdade. Eles farão SARESP.

Alana (Ciências): Exato, não temos a opção de não fazer. [...] por mais que eu esteja preocupada com o aprendizado dos alunos, lá irão focar somente no resultado. Para eles, mesmo que o aluno não compreendeu nada, mas atingiu os resultados, está ótimo. Eu me preocupo com o aprendizado, lá eles se preocupam com o resultado.

Os professores demonstram preocupação com os alunos que não aprendem e com os conteúdos curriculares a serem ensinados na escola. Explicitam o trabalho em função da avaliação externa quando citam o Saresp. Todas as possibilidades de trabalho com a singularidade das práticas naquela escola encontram-se amarradas pela avaliação externa, na medida em que esta circunscreve os conteúdos, matematiza e quantifica seus alunos, provocando desânimo geral já no início do ano quando há a apresentação dos resultados da avaliação do Saresp.

A pesquisa permite-nos afirmar, com os professores, que as avaliações externas, foco das atuais políticas de responsabilização em educação no país, provocam um atravessamento ao trabalho pedagógico que vem sendo desenvolvido pela equipe escolar. As três primeiras falas sinalizam a profunda influência que as avaliações exercem sobre a organização do trabalho na escola e, principalmente no trabalho que o docente desenvolve, "pois é o que cai nos exames, no vestibular", "nesse final de semestre tudo se volta para o SARESP", e "porque você precisa colocar o conceito no papel".

A fala de Alana ressalta importante elemento para nosso diálogo, que parece confirmar o fato de que, a percepção dos docentes acerca das necessidades de aprendizado por parte dos alunos não é contemplada nas determinações externas para o desenvolvimento do trabalho na escola, porque por mais que a docente "esteja preocupada com o aprendizado dos alunos, lá irão focar somente no resultado. Para eles, mesmo que o aluno não compreendeu nada, mas atingiu os resultados, está ótimo. Eu me preocupo com o aprendizado, lá eles se preocupam com o resultado".

Acreditamos que a tendência dos processos de avaliação externa deveriam visar a maximização da qualidade da educação e, em progressão, a diminuição dos problemas que eles refletem. Para isso os resultados deveriam condensar-se em políticas públicas de atendimento a demandas reais. Contudo, parece que a cultura da avaliação instaura a marca 
do estado gerencialista, visando o desenvolvimento técnico e científico na qualidade de mecanismos de apropriação do desenvolvimento econômico, pois

\begin{abstract}
a presença do "Estado avaliador" na educação promove um ethos competitivo pelas avaliações externas e pelo predomínio de uma racionalidade instrumental e mercantil que tende a supervalorizar indicadores e resultados acadêmicos quantificáveis e mensuráveis a despeito de contextos e processos educativos específicos. Através da avaliação pode-se dar aumento (neoconservador) do poder de controle central do Estado em torno dos currículos, da gestão das escolas e do trabalho dos professores. Pode também ocorrer a indução e implementação (neoliberal) de mecanismos de mercado no espaço público estatal e educacional, neste caso, em função das pressões de alguns setores sociais mais competitivos e das próprias famílias. (COELHO, 2008, p.249).
\end{abstract}

Além do atravessamento provocado pelas avaliações externas no trabalho docente, é necessário pontuar que, sendo preparadas em descolamento da realidade vivida e enfrentada no interior do espaço da escola, focando somente as diretrizes externas, as avaliações podem reforçar a relação de "fracasso escolar" ao evidenciar apenas falhas e, sobretudo por não levarem em conta a particular reciprocidade existente na materialidade da vida do aluno que está dada entre o indivíduo, a sociedade e a escola. Dessa maneira, é necessário questionar: as avaliações externas e em larga escala possuem condições de contemplar as relações que os alunos estabelecem nas disciplinas escolares? Ainda que, na perspectiva de Charlot, as disciplinas que podem direcionar-nos à teoria da relação com o saber devem contemplar "um sujeito, em relação com outros sujeitos, presa da dinâmica do desejo, falante, atuante, construindo-se em uma história, articulada com a de uma família, de uma sociedade, da própria espécie humana, 'engajado em um mundo no qual ocupa uma posição e onde se inscreve em relações sociais"? (CHARLOT, 2000, p.87-88).

Dessa maneira, é possível inferir que::

No Brasil, embora a autonomia dos estabelecimentos de ensino básico, discutida desde meados dos anos oitenta, seja mais retórica do que real, ela é uma justificativa para a avaliação e para a responsabilização dos profissionais da escola e, ainda, por efeito simbólico, vincula-se a uma nova representação sobre o papel do Estado, que está cada vez mais distante das funções de bem-estar social e das obrigações que assumira quando era o principal provedor e fornecedor de bens e serviços educativos. (COELHO, 2008, p. 249).

Acreditamos que é necessário que as determinações políticas, bem como a forma em que se empregam as avaliações, culminem na elaboração efetiva das políticas públicas e que essas não estejam descoladas do que é enfrentado na realidade das relações estabelecidas nas escolas, tanto pelos enfrentamentos dos alunos quanto pelo trabalho docente. Se pontuarmos 
que a construção da educação e das políticas públicas devem caminhar em consonância com os elementos constitutivos da materialidade da vida, falamos, portanto, do estabelecimento e da valorização do diálogo democrático levado às últimas consequências, ou seja, a retomada do entendimento da educação como direito social que está em jogo. Para tanto, é necessário compreendermos que:

\begin{abstract}
O acesso ao direito à educação não se empreendeu como reconhecimento político de coletividades historicamente subalternizadas, mas como ingresso de seus membros mais capazes por meio de um sistema neutro, objetivo e impessoal. Além de reduzir a concepção de educação a 'fator econômico' da produção capitalista descolado das relações sociais, éticas e culturais, o predomínio dessa perspectiva termina por culpabilizar a vítima de seu fracasso individual e por ocultar as desigualdades no acesso, no percurso e na qualidade da escola pública. (RODRIGUES, 2009, p. 3).
\end{abstract}

Com isso, ressaltamos que a tendência é tomar a causa do fracasso escolar pela origem social do aluno, designada sob a ótica da deficiência cultural. Bernard Charlot posiciona-se contrariamente a encarar essa tendência como verdadeira, pois::

\begin{abstract}
Afirmar que a origem social é a causa do fracasso escolar é cometer dois erros. Por um lado, significa passar de variáveis construídas pelo pesquisador para realidades empíricas [...]. Por outro, é interpretar um vínculo, também construído em termos de causa efetiva, de ação empírica. É verdade que o fracasso escolar "tem alguma coisa a ver" com a origem social [...] mas a origem social não produz o fracasso escolar. (CHARLOT, 2000, p.25).
\end{abstract}

A diferença social, que demonstra uma posição, assume a determinação de origem, cristalizando dessa forma o fracasso. Poderíamos erroneamente inferir que, se a posição social, que expressa diferença, é a origem do fracasso escolar, todos os alunos de camadas populares que forem inseridos no espaço escolar devem ser considerados fracassados. Interpretando esse princípio em relação ao aluno, Charlot pontua que:

\begin{abstract}
Ao constatar uma "falta" no fim da atividade, essa falta é projetada, retroprojetada, para o inicio dessa atividade: faltam ao aluno em situação de fracasso recursos iniciais, intelectuais e culturais, que teriam permitido que o aprendizado (e o professor...) fosse eficaz. [Assim se determina:] ele é deficiente. (CHARLOT, 2000, p. 27).
\end{abstract}

Nesses termos, a escola não teria sentido, pois sua função seria a de aniquilar qualquer possibilidade de alteração social, posto que seus padrões estariam por determinar uma sociedade estática diante daqueles que não se enquadram em tipos ideais, pois sua realidade não foi composta pelos elementos que dele agora esperam em sinal de resposta a espaços, tempos e métodos engessados, que reforçam o erro em vez de promover condições para acertos. 
O que ocorre nesses casos é a cristalização das deficiências por uma função discursiva, e se dá pelo posicionamento da determinação e não da relação, relação com o saber. Pontua-se no aluno, em todos os elementos que compõem sua existência, uma ausência, uma privação, ou seja, "tal falta é pensada como uma característica do aluno: ele é um deficiente sociocultural”. (CHARLOT, 2000, p. 26).

Ao pontuar que o "fracasso escolar" não existe, Charlot nos apresenta argumentos consistentes para abordar a problemática por considerar que todos os fenômenos abarcados na realidade interpretativa da relação de fracasso são reais, existem, mas nenhum desses objetos é analisável redutivamente com sendo determinante do "fracasso escolar". (2000, p. 16). Parece-nos claro que, sintetizar todos esses elementos em um único objeto, culmina na pontuação de ser esse objeto a figura do aluno (não raro a dos professores), ou seja, tem se tornado comum que a figura do aluno concentre o ponto da discussão e que boa parte dos argumentos que carregam a negatividade de determinado objeto acabem por culpabilizar a figura do aluno.

A criação desse cenário acaba por colocar alunos e professores em situação de fracasso como objeto do "fracasso escolar", e ideologicamente a cristalizar as deficiências sociais. O plano de imanência que corresponde ao horizonte de nossas possibilidades é problematizar o espaço escolar pautando nosso trabalho no trabalho coletivo em detrimento às determinações oficiais prescritivas.

\section{REFERÊNCIAS}

BAKTHIN, Mikhail. Marxismo e filosofia da linguagem. São Paulo: Hucitec, 2002.

BONAMINO, Alicia; SOUSA, Sandra Zákia. Três gerações de avaliação da educação básica no Brasil: interfaces com o currículo da/na escola. Educação e Pesquisa, São Paulo, v. 38, n. 2, p. 373-388, abr.-jun. 2012.

BOURDIEU, Pierre; PASSERON, Jean Claude. A reprodução: elementos para uma teoria do sistema de ensino. Rio de Janeiro: Francisco Alves, 1975.

CHARLOT, Bernard. Da relação com o saber: elementos para uma teoria. Trad. Bruno Magne. Porto Alegre: Artmed, 2000.

CHARLOT, Bernard. Relação com o saber, formação de professores e globalização: questões para a educação hoje. Porto Alegre: Artmed, 2005. 
COELHO, Maria Inês de Matos. Vinte anos de avaliação da educação básica no Brasil: aprendizagens e desafios. Ensaio: aval. pol. públ. educ., Rio de Janeiro, v. 16, n. 59, p.229258, abr./jun. 2008.

CRISTOFOLETI, Rita de Cássia; MARTANI, Bárbara Fernanda; OMETTO, Cláudia Beatriz Castro Nascimento. Um olhar para a sala de aula e para as crianças que não aprendem: considerações sobre a questão do fracasso escolar. In: CAPELLINI, Vera Lucia Messias Fialho et al. (Org.). Formação de professores: compromissos e desafios da educação pública. São Paulo: Cultura Acadêmica, 2013. p. 539-545. v. 2

FOUCAULT, Michel. A ordem do discurso: aula inaugural no Collége de France, pronunciada em 2 de Dezembro de 1970. 17. ed. São Paulo: Loyola, 2008. Disponível em: <http://www.inep.gov.br/imprensa/noticias/outras/news03 19.htm> Acesso em 20 de nov. 2012.

JAEGER, Werner. Paideia: a formação do homem grego. 5. ed. São Paulo: WMF Martins Fontes, 2010.

MARIGUELA, Adriana Duarte Bonini; SENICATO, Renato Bellotti. A educação como efeito multiplicador. In: SILVA, Luzia Batista de Oliveira et. al. (Org). O diálogo em educação: uma caminho ou uma nova paideia para uma reflexão sobre a educação em uma sociedade de consumidores. São Carlos: Pedro \& João Editores, 2013.

RODRIGUES, Rubens Luiz. Democratização e cultura no debate educacional brasileiro: tensões e articulações entre igualdade e pluralidade. Vertentes, São João Del Rei, v. 1, n. 33, p.9-20, jan./jun. 2009.

SOARES, Magda. Linguagem e escola: uma perspectiva social. 10.ed. São Paulo: Ática, 2002.

TRÓPIA, Guilherme; CALDEIRA, Ademir Donizeti. Vínculo entre relação com o saber de Bernhard Charlot e categorias bachelardianas. Educação, Porto Alegre, v.34, n. 3, p. 369375, set./dez. 2011.

VIGOTSKI, Lev Semenovitch. A formação social da mente. São Paulo: Martins Fontes, 1989.

\section{Como citar este documento:}

SENICATO, Renato Bellotti; OMETTO, Cláudia Beatriz de Castro Nascimento. Discutindo sobre o fracasso escolar na perspectiva de Bernard Charlot: em foco uma escola pública paulista de educação básica. ETD - Educação Temática Digital, Campinas, SP, v. 16, n. 2, p. 249-267, maio/ago. 2014. ISSN 1676-2592. Disponível em: <http://www.fe.unicamp.br/revistas/ged/etd/article/view/6434>. Acesso em: 29 ago. 2014. 